\title{
Vertical Dynamic Analysis of Ballastless Tracks on Train-Track- Bridge System
}

\author{
Haoran Xie ${ }^{1,2,}$, Bin $\mathrm{Yan}^{1,2}$, Jie Huang ${ }^{1,2}$ \\ ${ }^{1}$ School of Civil Engineering, Central South University, Changsha, China \\ ${ }^{2}$ National Engineering Laboratory for High Speed Railway Construction, Changsha 410075, China
}

\begin{abstract}
In order to investigate the vertical dynamic response characteristics of train-track-bridge system on CWR (Continunously Welded Rail) under dynamic load of train on HSR (High-Speed Railway) bridge. Based on the principle of vehicle train-track-bridge coupling dynamics, taking the $32 \mathrm{~m}$ simply supported bridge of a section of Zhengzhou-Xuzhou Passenger Dedicated Line as an example, the finite element software ANSYS and the dynamic analysis software SIMPACK are used for co-simulation, and bridge model of the steel spring floating slab track and the CRTSIII ballastless track (China Railway Track System) considering the shock absorbing steel spring, the limit barricade and the contact characteristics of track structure layers are established. On this basis, in order to study the dynamic response laws of the design of ballastless track structure parameters to the system when the train crosses the bridge and provide the basis for the design and construction, by studying the influence of the speed of train on the bridge, the damage of fasteners and the parameters of track structure on the train-track-bridge system, the displacement of rail, vertical vibration acceleration and wheel-rail force response performance are analyzed. Studies have shown that: At the train speed of $40 \mathrm{~km} / \mathrm{h}$, the displacement and acceleration of the rail and track slab in the CRTSIII ballastless track are smaller than the floating slab track structure, but the floating slab track structure has better vibration reduction performance for bridges. The acceleration of rail, track slab and bridge increases obviously with the increase of train speed, the rail structure has the largest increasement. Reducing the stiffness of fasteners could decrease the vertical acceleration response of the steel spring floating slab track system, the ability to absorb shock can be enhanceed by reducing the stiffness of the fastener appropriately. Increasing the density of the floating slab can increase the vertical acceleration of the floating slab and the bridge, thereby decreasing the vibration amplitude of the system.
\end{abstract}

\section{Introduction}

In recent decades, the world railway ballastless track structure is mainly characterized by HSR (High-Speed Railway) in Germany and Japan. At present, with the rapid development of Chinese railways, in order to eliminate the dynamic impact of traditional seamed rails, the CWR (Continunously Welded Rail) is widely used. For protecting the environment, reduceing the occupation of cultivated land and preventing foundation settlement, as well as the need to cross complex terrain and existing lines, CWR is commonly laid on bridges rather than the subgrade [1]. For example, the BeijingShanghai HSR subgrade section is only $18.5 \%$, and the rest of the lines are arranged on the bridges. Such as the CRTSI double block ballastless track, the CRTSII longitudinal ballastless track, the CRTSIII ballastless track and the steel spring floating slab track [2]. Among them, the CRTSIII ballastless track on the bridge adopts the unit block structure where there is an intermediate isolation layer between the baseplate and the selfcompacting concrete (SCC) layer, and using the limit barricade to transmit the longitudinal and lateral forces of the track [3]; As for the steel spring floating slab track, it floats the concrete slab with a certain quality and stiffness on the steel spring isolator, $30 \mathrm{~mm}$ away from the top surface of the base cushion, which forms the mass-spring-foundation isolation system [4]. Domestic and foreign scholars have carried out extensive and profound researchs on the mechanics and deformation performance of ballastless track under the action of trains, including foundations and situations such as subgrade [5], simple-supported bridge and steel-concrete bridge [6], seismic response [7], mortar layer separation [8-9], track slab structure voiding [10], damage induced by temperature stress [11] and the CRTS series track types [12-13]. The vibration and impact of the system can be greatly reduced due to CWR on the bridge using ballastless track. In view of the special structure of CRTSIII ballastless track and steel spring floating slab track, the vibration mechanism and time-history characteristics of the train-track-bridge system are not very clear. In addition, there are a little of studies on the influence of train speed and fastener stiffness on the dynamic performance of the system and the cosimulation of $3 \mathrm{D}$ entities.

\footnotetext{
* Corresponding author: m15955099594@163.com
} 
In order to explore the dynamic response of the ballastless track on CWR bridge, based on the traintrack-bridge coupling dynamics principle, and take a $32 \mathrm{~m}$ simple box girder bridge of Zheng-Xu Passenger Dedicated Line as an example. Based on the method of ANSYS+SIMPACK co-simulation, the modal analysis is carried out to investigate the dynamic response of the system under the parameters of the structure itself, the fastener damage and the train speed, at the same time, the dynamic characteristics such as vertical displacement, vibration acceleration and wheel-rail force are discussed.

\section{Spatial simulation model of train- track-bridge system}

\subsection{Vibration model of the system}

The infinite-length "Eular beam" supported by the elastic point is adopted, and the three-dimension stiffness and damping coefficient spring are used to simulate the constraint of the $\mathrm{WJ}-8 \mathrm{C}$ fastener on the rail structure. The track slab and baseplate are regarded as double-layer elastic composite beam [14] as the reference mass, as shown in Figure 1.

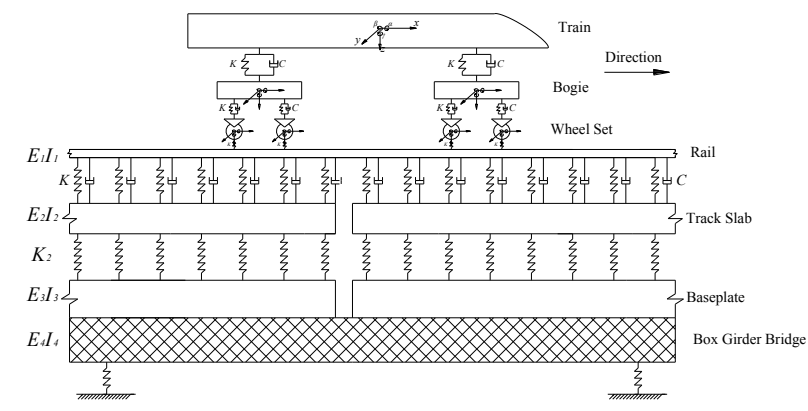

(a) Vibration model

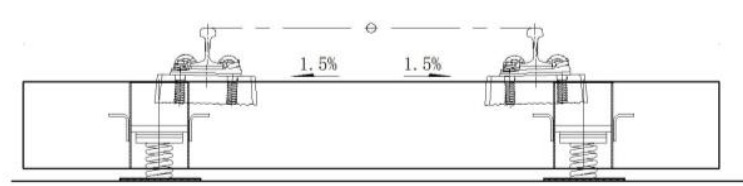

(b) Steel spring floating slab track

Fig. 1. Schematic diagram of system structure

\subsection{Vehicle dynamics model}

Based on the CRH3 type train in China, a multi-body dynamics spatial simulation model is established, which is mainly composed of a rigid body, a spring and a damper, including a train body, a bogie, four wheelsets, a suspension system and a secondary suspension system, with a total of 35 DOF. Among them, the weight of the wheel set is $1200 \mathrm{~kg}, 3200 \mathrm{~kg}$ for the frame, and $48,000 \mathrm{~kg}$ for the train body. Besides, the track irregularity adopts the American grade six spectrum.

\subsection{FEM of track-bridge system}

Simply supported box girder is supported by fixed + active mode, the finite element model of steel spring floating slab track and CRTSIII ballastless track is established, respectively. (Fig. 2)

Structural parameters are shown in the table 1 below:

Table 1. Structural parameters

\begin{tabular}{|c|c|c|c|c|}
\hline \multirow{2}{*}{$\begin{array}{c}\text { Material } \\
\text { Values }\end{array}$} & \multicolumn{4}{|c|}{ CRTSIII Ballastless Track } \\
\cline { 2 - 5 } & $\begin{array}{c}\text { Track } \\
\text { slab }\end{array}$ & SCC & Baseplate & Bridge \\
\hline $\begin{array}{c}\text { Elastic } \\
\text { modulus/GPa }\end{array}$ & 35.5 & 32.5 & 32.5 & 33.5 \\
\hline Poisson ratio & 0.2 & 0.2 & 0.2 & 0.2 \\
\hline $\begin{array}{c}\text { Density/ kg• } \\
\mathrm{m}^{-3}\end{array}$ & 2500 & 2500 & 2500 & 2500 \\
\hline $\begin{array}{c}\text { Moment of } \\
\text { inertia/m }\end{array}$ & - & - & - & 10.76 \\
\hline $\begin{array}{c}\text { Material } \\
\text { Values }\end{array}$ & Steel Spring Floating Slab Track \\
\cline { 2 - 5 } & Floating slab & Bridge \\
\hline $\begin{array}{c}\text { Elastic } \\
\text { modulus/GPa }\end{array}$ & \multicolumn{3}{|c|}{32.5} & 32.5 \\
\hline Poisson ratio & \multicolumn{3}{|c|}{0.2} & 2500 \\
\hline $\begin{array}{c}\text { Density/ kg• } \\
\mathrm{m}^{-3}\end{array}$ & \multicolumn{3}{|c|}{3000} & \multicolumn{2}{c|}{10.83} \\
\hline $\begin{array}{c}\text { Moment of } \\
\text { inertia/m }\end{array}$
\end{tabular}

Among them, Solid45 element is used to simulate the structure of bridge and track structures, and Target 170 and Contact174 element are used in ANSYS to simulate the surface-surface contact between the track layers.

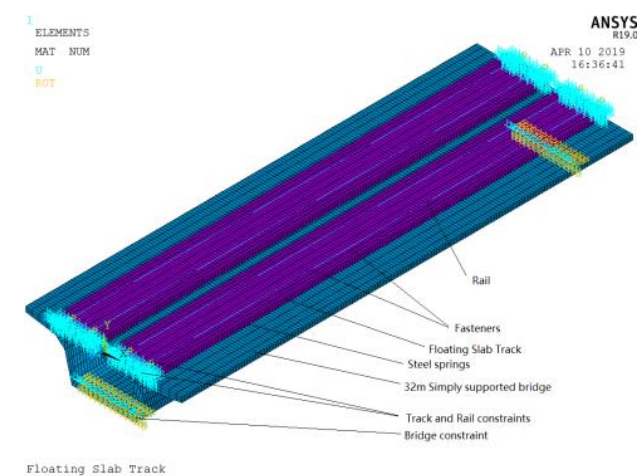

(a) FEM of floating slab track

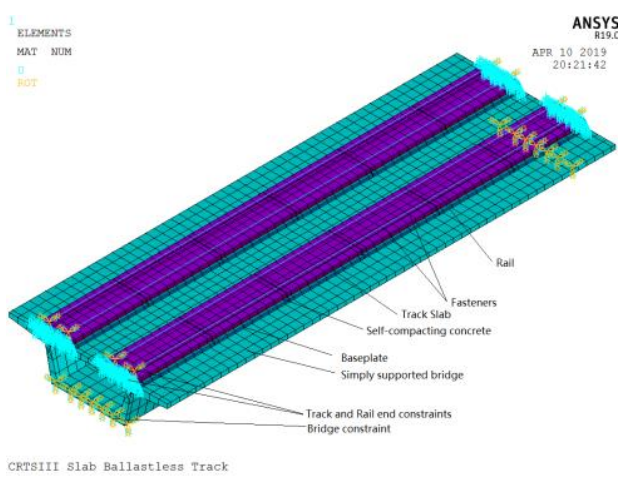

(b) FEM of CRTSIII slab ballastless track

Fig. 2. FEM of ballastless track on bridge 
Based on the two type ballastless track models show in above, the multi-body dynamics simulation model of train-track-bridge is established. (Fig. 3)

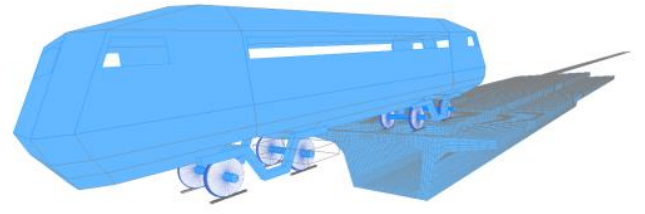

$\Gamma$

(a) System coupling model

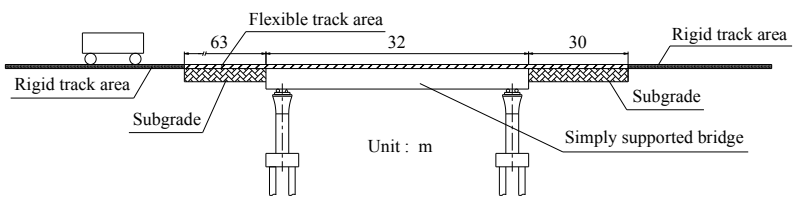

(b) Location layout

Fig. 3. Schematic diagram of train-track-bridge coupling model

\section{Characteristics of dynamic response of different track types on bridge}

\subsection{Dynamic response of CRTSIII ballastless} track

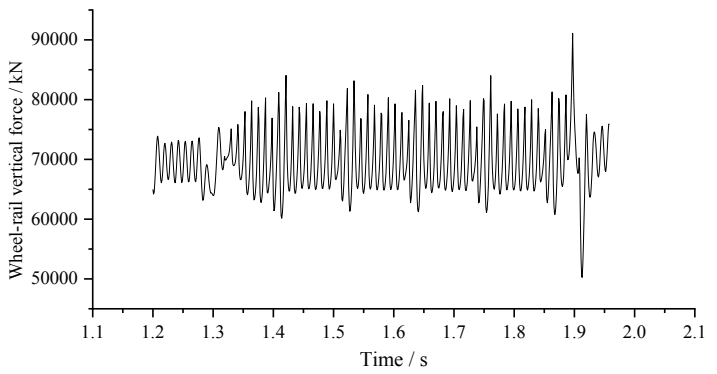

(a) Wheel-rail vertical force

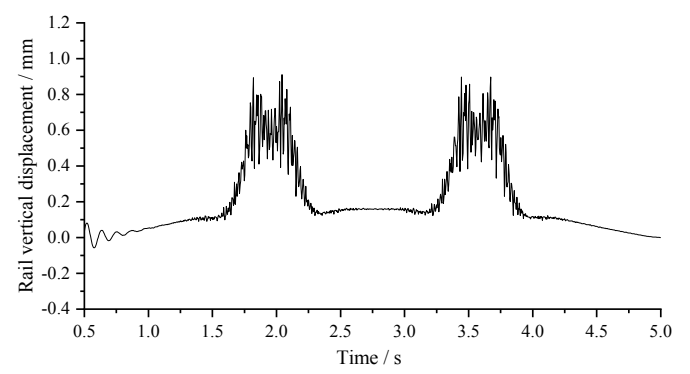

(b) Vertical displacement of rail

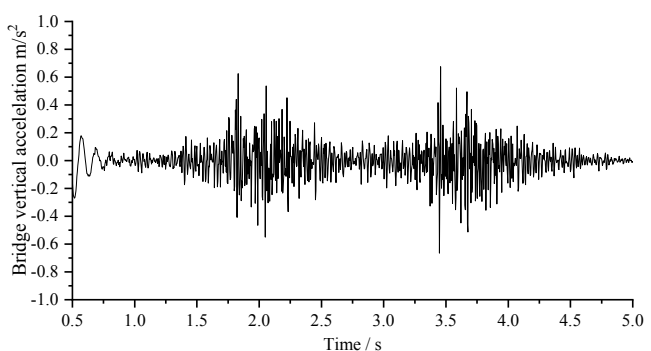

(c) Vertical acceleration of bridge

Fig. 4. Dynamic Response of CRTSIII

In Figure 4, the dynamic response under the train dynamic action of the CRTSIII ballastless track is given, and it can be clearly seen in Fig (a) that when the train passes through the track slab seam, the wheel-rail interaction surges, and the vertical force of them increases sharply by $10.4 \%$. Attention should be paid to the dynamic response law of the train body at the $0.07 \mathrm{~m}$ slab seam of adjacent track slab. By observing the timehistory curve of the displacement of the steel spring floating slab, it can be found that the curve tendency of the displacement of floating slab is very similar to that of rail structure, and it's going to be m-shaped. The maximum vertical displacement of the rail is $0.93 \mathrm{~mm}$, and the maximum acceleration of the bridge is $0.71 \mathrm{~m} / \mathrm{s}^{2}$, both of which increase significantly at both ends of the bridge, and the dynamic response in the mid-span region is relatively small.

\subsection{Dynamic response of steel spring floating slab track}

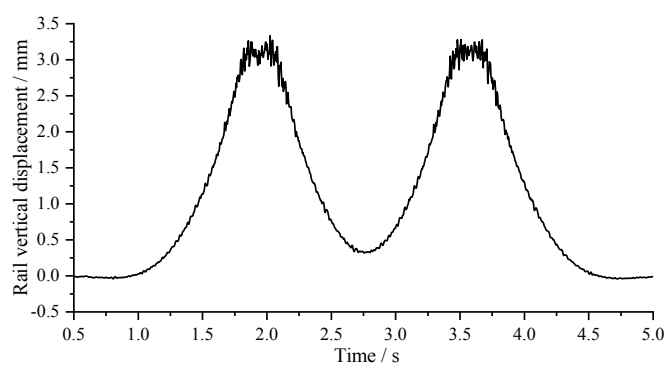

(a) Vertical displacement of rail

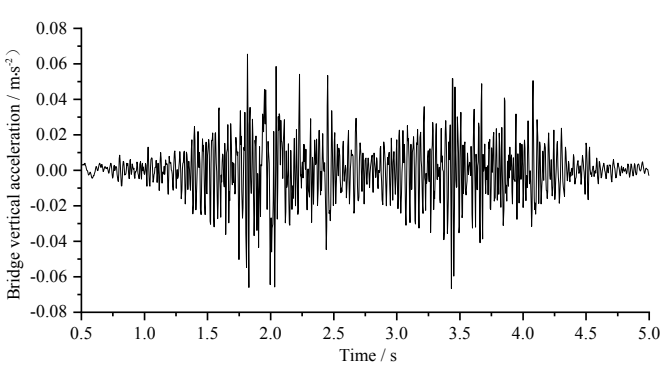

(b) Vertical acceleration of bridge

Fig. 5. Dynamic response of steel spring floating slab track

Figure 5 shows the system dynamic response of a 40 $\mathrm{km} / \mathrm{h}$ train speed of the floating slab track.

By comparing the dynamic response of the CRTSIII ballastless track structure and the steel spring floating slab track structure, it can be found that the vertical displacement of the rail structure of the floating slab track in Fig (a) is greater than that of the the III type track structure. The maximum rail vertical displacement of the floating slab track is $3.33 \mathrm{~mm}$, and $0.93 \mathrm{~mm}$ for CRTSIII ballastless track. It can be found from the comparison of rail vertical displacement time-history curve that the stiffness of floating slab track structure is less than that of the CRTS track structure due to the 
installation of steel spring shock absorber. In Fig (b), the tendency of curves of bridge vertical acceleration is similar, but the floating slab track structure of bridge are much smaller than that of CRTSIII track. In conclusion, the vibration damping performance of floating slab track structure is better.

\section{Influencing factors on dynamic response of steel spring floating slab track}

Combined with the actual train operating conditions, for the ballastless track structure of shock-absorbing steel spring floating slab, the factors such as train speed, fastener stiffness, floating slab density and other parameters have a great impact on the track structure. Therefore, it is necessary to select these three factors to analyze the dynamic response of train-track-bridge system and provide basis for design and construction.

\subsection{Effect of train speed on vertical dynamic response}

When analyzing the influence of speed on vertical dynamic response, the operating speeds are $20 \mathrm{~km} / \mathrm{h}$, $40 \mathrm{~km} / \mathrm{h}, 60 \mathrm{~km} / \mathrm{h}$, and $80 \mathrm{~km} / \mathrm{h}$, respectively. And the other parameters of the model remain unchanged. The calculation results are shown in Table 2.

Table 2. Vertical dynamic response of steel spring floating slab track system on bridge under different speed

\begin{tabular}{|c|c|c|c|c|}
\hline Item & A & B & C & D \\
\hline Speed $(\mathrm{km} / \mathrm{h})$ & 20 & 40 & 60 & 80 \\
\hline Rail displacement $(\mathrm{mm})$ & 3.25 & 3.33 & 3.45 & 3.57 \\
\hline Slab displacement $(\mathrm{mm})$ & 2.73 & 2.77 & 2.75 & 2.76 \\
\hline Bridge displacement $(\mathrm{mm})$ & 0.24 & 0.25 & 0.24 & 0.24 \\
\hline Rail acceleration $\left(\mathrm{m} / \mathrm{s}^{2}\right)$ & 169 & 370 & 507 & 584 \\
\hline Slab acceleration $\left(\mathrm{m} / \mathrm{s}^{2}\right)$ & 3.56 & 6.12 & 7.40 & 9.55 \\
\hline Bridge acceleration $\left(\mathrm{m} / \mathrm{s}^{2}\right)$ & 0.042 & 0.065 & 0.074 & 0.089 \\
\hline
\end{tabular}

With the increase of the train speed, compared with the floating slab and bridge structure, the vertical displacement of the rail increases more obviously, 9.8\%. In addition, the acceleration of the rail, the floating slab and the bridge is obviously increased. Among them, the increase of the rail structure is up to $245.6 \%$, and $168.3 \%$ for floating slab, $112 \%$ for bridge. The dynamic effect of the wheel-rail system is significantly increased, and the wheel load shedding rate and the derailment coefficient are slightly increased. Therefore, in order to reduce the vibration of the special section, the appropriate speed limit of the subway train can be carried out in the vibration-damping section.

\subsection{Influence of fastener stiffness on vertical dynamic response}

The fastener stiffness has great significance to the dynamic response of the train-track-bridge system. The stiffness variation in the actual environment will significantly affect the train operation safety, resulting in the change of the geometric shape of the track structure. The fastener stiffness is $1.5 \mathrm{e} 7 \mathrm{~N} / \mathrm{m}, 3 \mathrm{e} 7 \mathrm{~N} / \mathrm{m}, 4.5 \mathrm{e} 7 \mathrm{~N} / \mathrm{m}$, and $6 \mathrm{e} 7 \mathrm{~N} / \mathrm{m}$, respectively. The corresponding laws of system dynamics are given in Table 3.

Table 3. Vertical dynamic response under different fastener stiffness

\begin{tabular}{|c|c|c|c|c|}
\hline Item & A & B & C & D \\
\hline Stiffness $(\mathrm{N} / \mathrm{m})$ & $1.5 \mathrm{e} 7$ & $3 \mathrm{e} 7$ & $4.5 \mathrm{e} 7$ & $6.0 \mathrm{e} 7$ \\
\hline Rail displacement $(\mathrm{mm})$ & 3.77 & 3.33 & 3.15 & 3.11 \\
\hline Slab displacement $(\mathrm{mm})$ & 2.72 & 2.77 & 2.75 & 2.75 \\
\hline Bridge displacement $(\mathrm{mm})$ & 0.24 & 0.25 & 0.24 & 0.24 \\
\hline Rail acceleration $\left(\mathrm{m} / \mathrm{s}^{2}\right)$ & 239 & 292 & 367 & 444 \\
\hline Slab acceleration $\left(\mathrm{m} / \mathrm{s}^{2}\right)$ & 4.94 & 6.12 & 7.97 & 9.42 \\
\hline Bridge acceleration $\left(\mathrm{m} / \mathrm{s}^{2}\right)$ & 0.041 & 0.065 & 0.071 & 0.078 \\
\hline
\end{tabular}

As can be seen from table 3, with the fastener stiffness increases, the vertical displacement of the rail decreases significantly, $17.51 \%$. However, the vertical displacement of the floating slab and the bridge does not change significantly. Therefore, the rail is more sensitive to the change of the fastener stiffness. In order to maintain the smoothness of the line, it should be ensured that the fastener stiffness can not be too small. Besides, the acceleration of the rails, floating slab and bridge increases to varying degrees. Therefore, reducing the rigidity of the fastener can reduce the acceleration of the of the steel spring floating slab track structure on bridge, thereby achieving the effect of shock absorption. However, the reduction in the stiffness of the fastener increases the vertical displacement of the rail. In summary, the fastener stiffness should be appropriately reduced under the premise of ensuring the geometric position of the track. This is consistent with the design principle of low stiffness fasteners for rail transit on the bridge.

\subsection{Effect of steel spring floating slab density on dynamic response}

In order to study the influence of the density of the steel spring floating slab on the vertical dynamic response of the track structure on the bridge, the density of the floating slab is $2.6 \mathrm{e} 3 \mathrm{~kg} / \mathrm{m}^{3}, 2.8 \mathrm{e} 3 \mathrm{~kg} / \mathrm{m}^{3}, 3.0 \mathrm{e} 3 \mathrm{~kg} / \mathrm{m}^{3}$ and $3.2 \mathrm{e} 3 \mathrm{~kg} / \mathrm{m}^{3}$, respectively. Other calculation parameters remain unchanged. The results are shown in Table 4.

Table 4. Vertical dynamic response under different floating slab density

\begin{tabular}{|c|c|c|c|c|}
\hline Item & A & B & C & D \\
\hline Density $\left(\mathrm{kg} / \mathrm{m}^{3}\right)$ & $2.6 \mathrm{e} 3$ & $2.8 \mathrm{e} 3$ & $3.0 \mathrm{e} 3$ & $3.2 \mathrm{e} 3$ \\
\hline Rail displacement $(\mathrm{mm})$ & 3.33 & 3.33 & 3.34 & 3.33 \\
\hline Slab displacement $(\mathrm{mm})$ & 2.75 & 2.76 & 2.78 & 2.76 \\
\hline Bridge displacement $(\mathrm{mm})$ & 0.23 & 0.23 & 0.25 & 0.23 \\
\hline Rail acceleration $\left(\mathrm{m} / \mathrm{s}^{2}\right)$ & 377 & 357 & 330 & 314 \\
\hline Slab acceleration $\left(\mathrm{m} / \mathrm{s}^{2}\right)$ & 6.25 & 5.99 & 5.86 & 5.53 \\
\hline Bridge acceleration $\left(\mathrm{m} / \mathrm{s}^{2}\right)$ & 0.073 & 0.060 & 0.052 & 0.042 \\
\hline
\end{tabular}

Increasing the density of the slab can reduce the vertical acceleration of the rail, the floating slab and the bridge, and the decline ratios were $16.7 \%, 11.5 \%$ and $42.5 \%$, respectively, but has little effect on the vertical 
displacement of them. Therefore, the affect of vibration damping can be increased by increasing the density of the floating slab.

\section{Conclusions}

Based on ANSYS+SIMPACK, the CRTSIII ballastless track and steel spring floating slab track on the $32 \mathrm{~m}$ simply supported box girder bridge are established considering the shock absorbing steel spring, the limit barricade and the contact characteristics of track structure layers.

The difference of dynamic response with different track types when the train passes has been studied. Taking the floating slab track system on the bridge as an example, the influence of train speed, fastener stiffness and the density of the floating slab on the dynamic characteristics of the train-track-bridge system is analyzed. The main conclusions obtained include:

(1) At the running speed of $40 \mathrm{~km} / \mathrm{h}$, the displacement and acceleration of the rail and track slab in the CRTSIII ballastless track structure are smaller than that of the floating slab track structure, but the bridge acceleration is obviously larger, so the ability to absorb shock of the floating slab track on the bridge more excellent.

(2) The acceleration of rail, floating slab and bridge increases with the increase of train speed. The increase of rail structure is up to $245.56 \%$, and the dynamic effect of wheel-rail system is significantly increased.

(3) Reducing the stiffness of the fastener will reduce the vertical acceleration of the rail, track slab and bridge. Under the premise of ensuring the geometric shape of the track, the stiffness of the fasteners should be appropriately reduced to achieve the effect of vibration reduction.

(4) Increasing the density of the floating slab has little effect on the vertical displacement of the system, but it can reduce the vertical acceleration of the floating slab and the bridge. The vibration amplitude of the system can be reduced by increasing the density of the floating slab.

The authors would like to thank the National Key R\&D Program of China (2017YFB1201204), National Natural Science Foundational of China (51608542) and Natural Science Foundation of Hunan Province(2017JJ3387).

\section{References}

1. B. Yan, G.L. Dai, N. Hu. Recent development of design and construction of short span high-speed railway bridges in China[J]. Engineering Structures. 100: 707-717, (2015)

2. Code for Design of High Speed Railway: TB 106212014[S], (2014)

3. J.J. Wang, M. Wang, W.B. Liu, Y. Zhao. Technology Of CRTS III Ballastless Track System[J]. Chinese Railways, (08):11-15, (2017)

4. M.H. Li, M. Ma, W.N. Liu, et al. Influence of static preload on vibration reduction effect of floating slab
tracks[J].Journal of Vibration and Control, 25(6):1148-1163, (2019)

5. Jiang, G. Hong, et al. "Geometry mapping and additional stresses of ballastless track structure caused by subgrade differential settlement under self-weight loads in high-speed railways." Transportation Geotechnics 18: 103-110, (2019)

6. Podworna, Monika.Dynamic response of steelconcrete composite bridges loaded by high-speed $\operatorname{train}[\mathrm{J}]$. Structural engineering and mechanics, 62(2):179-196, (2017)

7. B. YAN, S. LIU, H. PU, G.L. DAI, X.P. CAI. Elastic-plastic seismic response of CRTS II slab ballastless track system on high-speed railway bridges [J]. SCIENCE CHINA Technological Sciences, 60(6): 865-871, (2017)

8. Han J, Zhao G, Xiao X, et al. Effect of cement asphalt mortar damage location on dynamic behavior of high-speed track[J]. Advances in Mechanical Engineering, 10(4): 1687814018770779, (2018)

9. J.J. Ren, et al. "Criteria for repairing damages of CA mortar for prefabricated framework-type slab track." Construction and Building Materials, 110: 300-311, (2016)

10. J.J. Ren, X.B. Yan, G.H. Xu, K. Xu. Effects of Contact Loss underneath Concrete Roadbed on Dynamic Performances of Slab Track-Subgrade System [J]. Journal of Southwest Jiaotong University

11. Y. Tian, N. Zhang, H. Xia.Temperature effect on service performance of high-speed railway concrete bridges $[\mathrm{J}]$.Advances in structural engineering, 20(6):865-883, (2017)

12. J.F. Wang, et al. "Performance of Cement Asphalt Mortar in Ballastless Slab Track over High-Speed Railway under Extreme Climate Conditions." International Journal of Geomechanics 19.5: 04019037, (2019)

13. P. Wang,Q. Yi,C.Y. Zhao, et al.Elastic wave propagation characteristics of periodic track structure in high-speed railway[J].Journal of Vibration and Control, 25(3):517-528, (2019)

14. L. Xu, W.M. Zhai. Stochastic Model Used for Temporal-spatial Analysis of Vehicle-track Coupled Systems[J].Journal of the China Railway Society, 40(01):74-79, (2018) 